\title{
Development and validation of a liquid chromatography-tandem mass spectrometry assay for serum 25-hydroxyvitamin D2/D3 using a turbulent flow online extraction technology
}

\author{
Dustin R. Bunch, Abby Y. Miller and Sihe \\ Wang* \\ Department of Clinical Pathology, Cleveland Clinic, \\ Cleveland, $\mathrm{OH}$, USA
}

\begin{abstract}
Background: Vitamin D is important to health and disease. Liquid chromatography-tandem mass spectrometry (LC-MSMS) is considered the most accurate technology for quantification of serum 25-hydroxyvitamin D (25OHD) which is the best biomarker for estimating vitamin $\mathrm{D}$ nutritional status.

Methods: Serum was mixed with acetonitrile containing hexadeuterated 25-hydroxyvitamin $D_{3} \quad\left(d_{6}\right.$ $25 \mathrm{OHD} 3$ ) and centrifuged $10 \mathrm{~min}$ at $15,634 \times \mathrm{g}$. The supernatant was injected onto a turbulent flow preparatory column then transferred to a polar endcapped $\mathrm{C} 18$ analytical column. The mass spectrometer was set for positive atmospheric pressure chemical ionization.

Results: The analytical cycle time was $5.5 \mathrm{~min}$. Interand intra-assay CV for both analytes across three concentrations ranged from $3.8 \%$ to $14.2 \%$. The method was linear from 3.0 to $283.6 \mathrm{nmol} / \mathrm{L}$ for 25 -hydroxyvitamin $\mathrm{D}_{3}$ (25OHD3) and 4.6 to $277.9 \mathrm{nmol} / \mathrm{L}$ for 25-hydroxyvitamin $\mathrm{D}_{2}$ (25OHD2), with an accuracy of $88.7 \%-118.7 \%$ and $90.7 \%-100.3 \%$, respectively. No carryover or ion suppression was observed. Comparison with a radioimmunoassay using patient specimens $(n=527)$ showed a mean difference of $5.2 \%$, and diagnostic agreement of $80.9 \%$ with Deming regression of slope 0.867 , intercept 12.8 , standard error of estimate (SEE) 17.4, and $r=0.8425$.

Conclusions: The LC-MSMS method coupled with turbulent flow technology for serum 25OHD quantitation is rapid, efficient, and suitable for clinical testing. Clin Chem Lab Med 2009;47:1565-72.
\end{abstract}

Keywords: 25-hydroxyvitamin D; liquid chromatography; radioimmunoassay; tandem mass spectrometry; turbulent flow.

\footnotetext{
*Corresponding author: Sihe Wang, Head, Section of Clinical Biochemistry, Department of Clinical Pathology, Mail Code L11, 9500 Euclid Ave, Cleveland, OH 44195, USA Phone: +1-216-445-2634, Fax: +1-216-444-4414,

E-mail: wangs2@ccf.org

Received May 21, 2009; accepted August 3, 2009; previously published online October 21, 2009
}

\section{Introduction}

Vitamin D has been recognized as the sunshine vitamin and deficiency/insufficiency has been associated with poor bone metabolism, weak muscle strength, cancer risk and mortality, autoimmune disease, and cardiovascular disease (1-3). Recently published studies show links between vitamin $D$ and various diseases including muscle strength (4), cancer risk and mortality (5-7), insulin resistance (8), and cardiovascular disease (9).

There are two common types of vitamin D: cholecalciferol (D3) and ergocalciferol (D2). D3 is synthesized in the skin from 7-dehydrocholesterol in cell membranes upon exposure to UVB (290-320 nm). $\mathrm{D} 2$ is derived primarily from yeast and produced exogenously by UV irradiation of ergosterol $(2,10)$. Both dietary supplementation and sunshine exposure are effective in preventing vitamin D deficiency $(2,10)$. There is clear evidence that UV light exposure, consuming vitamin D-fortified food, and/or vitamin D supplementation has a positive impact on serum 25-hydroxyvitamin D (25OHD) concentrations, and adults can tolerate vitamin $\mathrm{D}$ at doses above the current dietary reference intake levels (11-13). Though both D2 and D3 have been used as supplements, D2 is less efficient compared with D3 for increasing serum $25 \mathrm{OHD}(10,14,15)$. However, long-term treatment with D2 and D3, 1000 IU daily, showed similar effectiveness in increasing serum 25OHD (16).

Vitamin D in circulation is metabolized to $250 \mathrm{HD}$ in the liver and further metabolized to the active metabolite, 1,25-dihydroxyvitamin $D[1,25(\mathrm{OH}) 2 \mathrm{D}]$ in the kidney (10). The concentration of $1,25(\mathrm{OH}) 2 \mathrm{D}$ is highly regulated by many factors including serum parathyroid hormone and phosphorus $(1,2)$. The halflives of vitamin D, 25OHD, and 1,25(OH)2D are $\sim 24 \mathrm{~h}$, 3 weeks, and $4 \mathrm{~h}$, respectively (17). Liver production of $25 \mathrm{OHD}$ is not regulated significantly and is primarily dependent on the availability of vitamin $D$ (17). Therefore, measuring total serum $250 H D$ is considered the best estimate of vitamin D nutritional status. It is now generally accepted that serum $250 \mathrm{HD}$ concentrations of $50 \mathrm{nmol} / \mathrm{L}(20 \mathrm{ng} / \mathrm{mL})$ and $75 \mathrm{nmol} / \mathrm{L}$ (30 $\mathrm{ng} / \mathrm{mL}$ ) are the cut-off thresholds for deficiency and insufficiency, respectively $(10,18,19)$. Vitamin D insufficiency is recognized as an epidemic issue in both children and adults $(1,10,20)$.

Immunoassays and chromatography-based methods have been used to measure 25OHD in serum or plasma. The International Vitamin D Quality Assess- 
ment Scheme demonstrated that most commercial $250 H D$ methods were capable of producing reliable results for samples containing only 25-hydroxyvitamin $\mathrm{D}_{3}$ (25OHD3), but most methods had significant bias compared to HPLC for samples with a substantial proportion of 25-hydroxyvitamin $\mathrm{D}_{2}$ (25OHD2) (21). Evaluation of current radioimmunoassay (RIA) and chemiluminescent methods for serum 25OHD using patient samples showed substantial variability among the six methods, and the same methods used in different laboratories (22). Compared to a HPLC method for 25OHD, significant positive proportional bias was observed for immunoassays in the range of 20-50 nmol/L in serum samples before the patients had D2 treatment. Also, all the immunoassays that were evaluated under-estimated the 25OHD2 in samples following D2 treatment (23). A comprehensive evaluation of seven methods using 291 EDTA plasma samples (277 had no detectable 25OHD2 and 14 had 25OHD2 between 5 and $8 \mathrm{nmol} / \mathrm{L}$ ) showed that all methods, except HPLC, demonstrated considerable negative bias compared to liquid chromatographytandem mass spectrometry (LC-MSMS) (24). For most immunoassays, the deviation was more significant at $25 \mathrm{OHD}>75 \mathrm{nmol} / \mathrm{L}$ compared with those $>75 \mathrm{nmol} / \mathrm{L}$ (24).

Most HPLC methods require lengthy sample preparation, including solid-phase extraction (25) and liquid-liquid extraction (26), with a long HPLC chromatography time ranging from 10 to $30 \mathrm{~min}$. Attention should be given to the late elution peaks which might interfere with the analysis of succeeding samples (25). Although LC-MSMS is considered the most accurate technology for $25 \mathrm{OHD}$ quantification $(17,27)$, $1 \alpha$-hydroxyvitamin $D_{3}(1 \alpha$ OHD3) (28) and the C3 epimer of 25OHD (3-epi 25OHD) (29) could be significant interferents due to the same molecular weight if not separated by LC. Most LC-MSMS methods employ deuterated 25OHD3 as internal standard. To improve ionization efficiency, some methods employ a derivatization strategy with a Cookson-type reagent (30) or Diels-Alder derivatization (31). For direct measurement, sample preparation could be cumbersome. In general, sample preparation includes protein precipitation followed by solid-phase extraction (32-34) or liquid-liquid extraction $(28,35,36)$. Turbulent flow technology is a robust and rapid online purification tool for high efficiency extraction $(37,38)$, and has been used for online sample cleaning for serum 25OHD quantification (29). Here, we report a simple and fast LC-MSMS method with online turbulent flow extraction. We compared this method with a RIA method using a large number of patient samples.

\section{Materials and methods}

\section{Reagents and solutions}

Methanol, acetone, acetonitrile, and isopropanol (Burdick and Jackson High Purity Solvent) were from VWR (West Chester, PA, USA). Type 1 water was from Millipore Synergy System (Billerica, MA, USA). 25OHD2 and 25OHD3 were $\geq 98 \%$ and $1 \alpha$ OHD3 was $\geq 97 \%$ pure by HPLC (SigmaAldrich, St. Louis, MO, USA). Hexadeuterated-25-hydroxyvitamin $D_{3} \quad\left(d_{6}-25 O H D 3\right)\left(99 \%{ }^{2} H\right)$ and hexadeuterated25-hydroxyvitamin $\mathrm{D}_{2}\left(\mathrm{~d}_{6}-25 \mathrm{OHD} 2\right)\left(99 \%^{2} \mathrm{H}\right)$ were procured from Medical Isotopes (Pelham, NH, USA). A turbo preparatory column, Cyclone-P $1.0 \times 50 \mathrm{~mm}$, and a polar endcapped C18 column, Hypersil GOLD aQ $2.1 \times 50 \mathrm{~mm}, 5 \mu \mathrm{m}$, were purchased from Thermo Fisher (Waltham, MA, USA). The solvent mixer (P/N G1312-87330) was from Agilent (Santa Clara, CA, USA). The sampling vials (Waters, Milford, MA, USA) were LC-MS certified and Axygen 96-well plates were from VWR. ClinChek Serum 25OHD2 and 25OHD3 controls were purchased from IRIS Technologies Inc (Olathe, KS, USA). A stock solution for each $250 \mathrm{HD} 3(\mathrm{nmol} / \mathrm{L}=2.496 \times$ $\mathrm{ng} / \mathrm{mL}), \mathrm{d}_{6}-25 \mathrm{OHD} 3(\mathrm{nmol} / \mathrm{L}=2.459 \times \mathrm{ng} / \mathrm{mL})$, and $25 \mathrm{OHD} 2$ $(\mathrm{nmol} / \mathrm{L}=2.423 \times \mathrm{ng} / \mathrm{mL}$ ) was made at a nominal concentration of $250 \mu \mathrm{mol} / \mathrm{L}$. The final stock concentration was calculated using a Beckman Coulter DU 800 UV/visible spectrophotometer (Fullerton, CA, USA) with molar extinction coefficients of 17,950 (39) for 25OHD2 and 18,000 (40) for $25 \mathrm{OHD} 3$ at $265 \mathrm{~nm}$. A set of calibration standards with combined 25OHD3 and 25OHD2 at 200.0, 100.0, 50.0, 25.0, and $12.5 \mathrm{nmol} / \mathrm{L}$ for $25 \mathrm{OHD} 3$ and 194.0, 97.0, 48.5, 24.3, $12.1 \mathrm{nmol} / \mathrm{L}$ for $25 \mathrm{OHD} 2$ was prepared by serial dilution in absolute ethanol and stored at $-70^{\circ} \mathrm{C}$. Ethanolic calibrators were used because human serum, bovine serum albumin, and commercial steroid free serum all contained significant amounts of 25OHD, based on our evaluation. To ensure the matrix difference did not have an adverse impact on quantification of patient samples, serum-based commercial controls were included in each run. In addition, serum-based samples with known added values were used in the precision and linearity studies to show the validity of ethanolbased calibrators. A precipitation/internal standard solution containing $\mathrm{d}_{6}-25 \mathrm{OHD} 3$ at $103.3 \mathrm{nmol} / \mathrm{L}$ in acetonitrile was stored at $-20^{\circ} \mathrm{C}$.

\section{Sample collection and preparation}

Blood was collected in Vacutainer tubes with no additives (BD, Franklin Lake, NJ, USA). The specimens were centrifuged immediately upon arrival at $\sim 1500 \times g$ at room temperature and assayed for $250 \mathrm{HD}$ by RIA. Leftover samples of serum were aliquoted, de-identified, and frozen at $-70^{\circ} \mathrm{C}$ for the comparison study. Sample preparation consisted of adding $250 \mu \mathrm{L}$ internal standard to $100 \mu \mathrm{L}$ of serum in either polypropylene microcentrifuge tubes or 96 well plates. After vortexing for $1 \mathrm{~min}$, the mixture was centrifuged for $10 \mathrm{~min}$ at $15,634 \times g$ for the microcentrifuge tubes and $3300 \times g$ for the 96 well plates. In the microcentrifuge tubes, the supernatant was transferred to sample vials and placed on the autosampler. The plates were directly loaded into the autosampler with $100 \mu \mathrm{L}$ of the supernatant injected into the system.

\section{Turbulent flow LC-MSMS method}

This method was developed on the Thermo TSO Quantum Access with a Cohesive front end using turbulent flow technology. Instrument software for this study consisted of Tune Master 1.5, Aria 1.6.1, and Xcalibur 2.0.7. The duplex Cohesive system consisted of a robotic sampling arm and a refrigerated sampling compartment for six 96-well plates followed by two parallel and independent inline degassers, binary HPLC pumps, and quaternary HPLC pumps. A solvent mixer was placed between the sample injection port and the turbo column to mix the different solvents in the samples (acetonitrile) and the mobile phase (methanol), which could cause significant peak broadening. Samples were loaded on the 
Cyclone-P turbo column which was washed afterwards. At the transfer step, $100 \mu \mathrm{L}$ of methanol from the transfer loop eluted the analytes from the Cyclone-P turbo column to the Hypersil GOLD aQ analytical column where separation occurred with an isocratic elution of $95 \%$ methanol. The total run time between two injections was $5.5 \mathrm{~min}$ if only one channel was used. The mass spectrometer was set to positive ion mode with the atmospheric pressure chemical ionization probe. The discharge current was set to $2.0 \mathrm{~A}$ with the capillary temperature at $200^{\circ} \mathrm{C}$ and the vaporizer temperature at $290^{\circ} \mathrm{C}$. The sheath gas was set to $55 \mathrm{U}$ and aux gas to $25 \mathrm{U}$. Multiple reaction monitoring was set at the transitions of $401.3 \rightarrow 383.2 \mathrm{~m} / \mathrm{z}$ for 25OHD3, $407.3 \rightarrow 389.2 \mathrm{~m} / \mathrm{z}$ for $\mathrm{d}_{6}-25 \mathrm{OHD} 3$, and $413.3 \rightarrow 395.0 \mathrm{~m} / \mathrm{z}$ 25OHD2. The collision energy was $8 \mathrm{eV}$ for 25OHD3 and 25OHD2 and $7 \mathrm{eV}$ for $d_{6}-25 O H D 3$ and the tube lens for 25OHD3 was $110 \mathrm{~V}$ and for $\mathrm{d}_{6}-25 \mathrm{OHD} 3$ and 25OHD2 was $130 \mathrm{~V}$. Data collection started at $2.5 \mathrm{~min}$ into the HPLC run and continued for $1.25 \mathrm{~min}$. A representative patient chromatogram is displayed in Figure 1A. The turbulent flow and HPLC methodology is outlined in Table 1.

\section{RIA assay}

The primary method for comparison was the DiaSorin RIA (Stillwater, MN, USA) which was linear from 17.5 to
$249.6 \mathrm{nmol} / \mathrm{L}$. The intra-day variation $(\mathrm{n}=10)$ was $6.0 \%$ at $34.4 \mathrm{nmol} / \mathrm{L}$ and $5.5 \%$ at $120.6 \mathrm{nmol} / \mathrm{L}$. Inter-day variation $(\mathrm{n}=15)$ was $11.0 \%$ at $36.9 \mathrm{nmol} / \mathrm{L}$ and $10.5 \%$ at $136.8 \mathrm{nmol} / \mathrm{L}$. The lower limit of quantification (LLOQ) was $17.5 \mathrm{nmol} / \mathrm{L}$.

\section{Validation methods}

Ion suppression was evaluated by post-column infusion of a pure deuterated 25OHD2 and 25OHD3 solution while patient samples were injected in the system. Two phospholipids (lyso-phosphotidylcholine C16:0 and C18:0) were monitored for potential coelution. Since $1 \alpha$ OHD3 has the same molecular weight as 25OHD3 and was noted in a previous publication (28) as a possible interferent, we performed testing by injecting an ethanolic solution containing both $1 \alpha \mathrm{OHD} 3$ and $25 \mathrm{OHD} 3$.

The limit of detection was assessed by running saline $(n=20)$ and was determined to be 3 standard deviations (SD) over the mean. A pool of patient samples with $<12.5 \mathrm{nmol} / \mathrm{L}$ of 25OHD2 and 25OHD3 was spiked with both 25OHD2 and 250HD3. Then, linearity was examined in triplicate by serially diluting the spiked pool with saline to achieve the appropriate concentrations. The LLOO was determined by the lowest concentration levels in the linearity study with accuracy within $100 \% \pm 20 \%$ and total CV within $20 \%$. Both intraassay and inter-assay CVs were determined using three

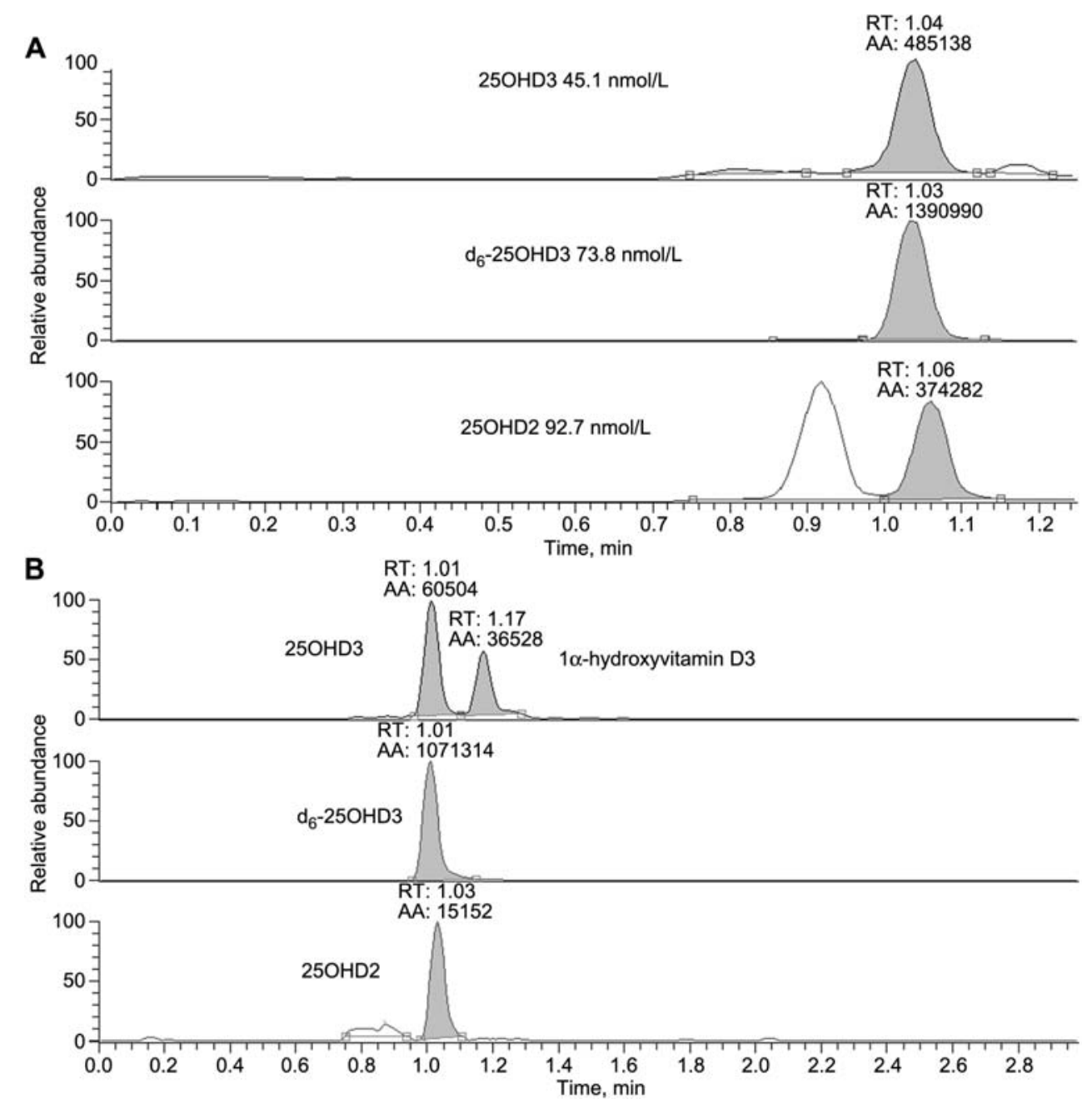

Figure 1 Chromatograms.

(A) A typical patient sample with mid levels of 25OHD2 and 25OHD3. Acceptable retention times (RT) for standards and patients are $25 \mathrm{OHD} 3$ and $\mathrm{d}_{6}-25 \mathrm{OHD} 3$ at $1.01 \pm 0.03 \mathrm{~min}$ and $25 \mathrm{OHD} 2$ at $1.04 \pm 0.03 \mathrm{~min}$. (B) Chromatographic resolution between $25 \mathrm{OHD} 3$ and $1 \alpha \mathrm{OHD} 3$ with $25 \mathrm{OHD} 3$ eluting at $1.01 \mathrm{~min}$ and $1 \alpha \mathrm{OHD} 3$ eluting at $1.17 \mathrm{~min}$. 
Table 1 LC conditions for turbo and analytical columns.

\begin{tabular}{|c|c|c|c|c|c|}
\hline Process & Time, s & $\begin{array}{l}\text { Turbo } \\
\text { column } \\
\text { solvent } \\
\text { A:B:C }\end{array}$ & $\begin{array}{l}\text { Flow rate, } \\
\mathrm{mL} / \mathrm{min}\end{array}$ & $\begin{array}{l}\text { Analytical } \\
\text { column } \\
\text { solvent } \\
\text { A:B }\end{array}$ & $\begin{array}{l}\text { Flow rate, } \\
\mathrm{mL} / \mathrm{min}\end{array}$ \\
\hline $\begin{array}{l}\text { Turbulent flow extraction } \\
\text { on turbo column }\end{array}$ & 55 & $60: 40: 0$ & 4.0 & $60: 40$ & 0.80 \\
\hline Slow down pumps & 5 & $60: 40: 0$ & 0.2 & $60: 40$ & 0.55 \\
\hline $\begin{array}{l}\text { Begin transfer from turbo } \\
\text { to analytical column }\end{array}$ & 90 & $60: 40: 0$ & 0.2 & $60: 40$ & 0.55 \\
\hline $\begin{array}{l}\text { Clean turbo column, perform } \\
\text { separation on analytical column }\end{array}$ & 45 & $0: 0: 100$ & 2.0 & $5: 95$ & 0.85 \\
\hline $\begin{array}{l}\text { Clean turbo column, perform } \\
\text { separation on analytical column }\end{array}$ & 30 & 100:0:0 & 2.0 & $5: 95$ & 0.85 \\
\hline $\begin{array}{l}\text { Load transfer loop and clean } \\
\text { analytical columns }\end{array}$ & 60 & $0: 100: 0$ & 4.0 & $0: 100$ & 0.85 \\
\hline $\begin{array}{l}\text { Equilibrate turbo and analytical } \\
\text { columns }\end{array}$ & 45 & $60: 40: 0$ & 4.0 & $60: 40$ & 0.80 \\
\hline
\end{tabular}

Mobile phase A, water; mobile phase B, methanol; mobile phase C, organic cocktail containing $70 \%$ acetonitrile, $20 \%$ isopropanol, and $10 \%$ acetone.

concentrations of patient samples in the sequence mid-highlow-mid-mid-low-low-high-high-mid run twice a day for 5 days using CLSI EP10-A3 guidelines (Wayne, PA, USA). Carryover was determined by analysis of three extractions of the sequence $\left(\operatorname{low}_{1}\right.$-high-low ${ }_{2}$ ) where low $_{2}$ was a re-injection of the low l $_{1}$. A passing test meant low $\mathrm{w}_{1}$ and low $_{2}$ differed by $<20 \%$ and the $\operatorname{low}_{2}$ was within 3 SDs of the low 1 value. The

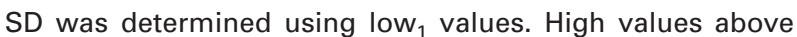
the linearity of the assay were diluted to within the linear range and the value was back calculated. Comparisons using Deming regression, Passing-Bablok regression, and analysis for diagnostic agreement were performed between the new LC-MSMS assay and the RIA method. Statistics were calculated using Excel (Microsoft, Redmond, WA, USA), EP Evaluator Release 8 (David G. Rhoads Associates, Kennett Square, PA, USA), and Analyze-it ${ }^{\circledR}$ (Analyse-it Software, Ltd, Leeds, UK).

\section{Ethical approval}

Utilizing leftover de-identified clinical samples did not require institutional Review Board review.

\section{Results and discussion}

\section{Chromatography}

During the chromatography optimization, we found that there was a narrow range of mobile phase compositions for efficiently retaining the 250HD analytes on the turbo column for purification. We found that $60 \%$ water with $40 \%$ methanol retained the analytes on the turbo column best, without causing peak broadening. Acid is often added to mobile phases for LC-MSMS because it improves ionization (41). Thus, formic acid was tested for ionization improvement by infusing the analytes and $d_{6}-250 H D 3$ in the presence of mobile phase with and without $0.1 \%$ formic acid. There was no significant difference between the two conditions. The chromatographic run time was $5.5 \mathrm{~min} /$ injection in a single channel. When two LC channels were used at the same time, the average run time in a batch was reduced to $3.0 \mathrm{~min} /$ injection.
The retention time (mean $\pm S D$ ) for $250 H D 3$ and $d_{6}$ $250 H D 3$ was $1.01 \pm 0.1 \mathrm{~min}(\mathrm{n}=571)$ and for $250 \mathrm{HD} 2$ was $1.04 \pm 0.1 \mathrm{~min}(n=432)$ in serum samples (Figure 1). There was a significant peak in the $250 \mathrm{HD} 2$ channel at $0.9 \mathrm{~min}$ (Figure 1A). A full spectra scan was performed (data not shown) and it was found to have a significantly different fragmentation spectrum compared with $25 \mathrm{OHD} 2$.

\section{Interferences}

Interferences are less common with LC-MSMS methods due to the inherent specificity of MSMS. However, a compound with the same molecular weight and ionization characteristics can possibly interfere. Interference studies were conducted by obtaining pure compound and spiking these into ethanolic standards with known 25OHD concentrations. This was injected into the system to see if it showed up on the chromatogram with a close retention time to the analytes. Due to previously published data, $1 \alpha \mathrm{OHD} 3$ was considered a possible interferent for 250HD3 and therefore was tested. The retention time of this compound was $1.17 \mathrm{~min}$ compared to $1.01 \mathrm{~min}$ for 25OHD3 with baseline separation (Figure 1B). In addition, a $250 \mathrm{nmol} / \mathrm{L}$ solution of $1 \alpha \mathrm{OHD} 3$ had a peak height similar to a $12.5 \mathrm{nmol} / \mathrm{L}$ peak of $250 \mathrm{HD} 3$ meaning a much lower ionization efficiency of $1 \alpha \mathrm{OHD} 3$ under the current conditions compared with 25OHD3. The 3-epi $250 H D$ is a known interferent for patients under the age of 1 year (29). At the time of method validation, a commercial 3-epi $250 \mathrm{HD}$ was not available for interference testing. Therefore, caution should be used for interpreting results in this age group. Other possible interferents are phospholipids found naturally in human blood. These compounds have similar characteristics as 25OHD2 and 25OHD3. Lyso-phosphotidylcholine C16:0 and C18:0 were monitored during development and showed no interference with either 250HD3 or 25OHD2 (data not shown). Also, due to their relatively high molecular weight (500-1000) compared to $250 \mathrm{HD}$, they were not 
Table 2 Linearity and recovery.

\begin{tabular}{lrrrrr}
\hline Analyte & $\begin{array}{l}\text { Add-in, } \\
\text { nmol/L }\end{array}$ & $\begin{array}{l}\text { Expected, } \\
\text { nmol/L }\end{array}$ & $\begin{array}{c}\text { Mean, } \\
\text { nmol/L }\end{array}$ & $\begin{array}{l}\text { Analytical } \\
\text { recovery, \% }\end{array}$ & $\%$ CV \\
\hline 25 OHD2 & 2.36 & 2.39 & 2.98 & 125.0 & 29.2 \\
& 4.73 & 4.78 & 4.60 & 96.2 & 4.3 \\
& 7.10 & 7.18 & 7.20 & 100.3 & 7.5 \\
& 9.46 & 9.57 & 9.45 & 98.8 & 6.9 \\
& 18.93 & 19.13 & 18.78 & 98.1 & 5.3 \\
& 37.86 & 38.26 & 36.66 & 95.8 & 4.8 \\
& 75.72 & 76.53 & 72.57 & 94.8 & 3.0 \\
25 OHD3 & 153.06 & 147.15 & 96.1 & 1.8 \\
& 151.44 & 306.12 & 277.92 & 90.7 & 14.5 \\
& 302.88 & 2.49 & 2.95 & 118.7 & 10.2 \\
& 2.44 & 7.98 & 5.42 & 109.0 & 3.1 \\
& 4.87 & 9.96 & 10.81 & 104.9 & 2.3 \\
& 7.31 & 19.92 & 18.89 & 94.7 & 3.9 \\
& 9.75 & 39.84 & 37.94 & 95.1 & 1.4 \\
& 19.50 & 79.68 & 72.63 & 91.0 & 2.3 \\
\hline
\end{tabular}

Table 3 Precision data according to CLSI EP10-A3 protocol.

\begin{tabular}{|c|c|c|c|c|c|c|}
\hline & \multicolumn{3}{|c|}{ 25OHD3 } & \multicolumn{3}{|c|}{ 25OHD2 } \\
\hline & Low & Mid & High & Low & Mid & High \\
\hline Mean, nmol/L & 33.4 & 61.0 & 120.5 & 18.5 & 70.6 & 139.9 \\
\hline Total SD & 3.0 & 4.6 & 11.4 & 3.1 & 7.8 & 15.6 \\
\hline Intra-assay SD & 1.6 & 2.3 & 7.4 & 1.7 & 3.2 & 9.0 \\
\hline Inter-assay \%CV & 7.7 & 6.6 & 7.1 & 14.2 & 10.0 & 9.2 \\
\hline Intra-assay \%CV & 4.9 & 3.8 & 6.1 & 9.3 & 4.6 & 6.4 \\
\hline
\end{tabular}

Table 4 Method comparison results by Deming regression.

\begin{tabular}{llllllll}
\hline $\begin{array}{l}\text { Comparison } \\
\text { method }\end{array}$ & Analyte & $\mathrm{n}$ & Slope $(95 \% \mathrm{Cl})$ & $\begin{array}{l}\text { Intercept, nmol/L } \\
(95 \% \mathrm{Cl})\end{array}$ & $\begin{array}{l}\text { Standard error of } \\
\text { estimate, nmol/L }\end{array}$ & $\begin{array}{l}\mathrm{r} \text { difference } \\
\text { of mean }\end{array}$ \\
\hline RIA & 25OHD & 527 & $0.867(0.825-0.909)$ & $12.8(9.5-16.1)$ & 17.4 & 0.8425 & 5.2 \\
RIA & 25OHD3 & 216 & $0.865(0.802-0.927)$ & $9.0(4.9-13.2)$ & 14.0 & 0.8595 & 1.7 \\
\hline
\end{tabular}

${ }^{\mathrm{a}}$ 25OHD2 is below LLOQ.

viewed as a major interferent (42). Ion suppression was examined by monitoring total ion current with 20 patient samples individually injected through a Tconnection with a post-column line prior to the mass spectrometer with a $d_{6}-25 O H D 3$ and $d_{6}-25 O H D 2$ ethanol solution infused at $5 \mu \mathrm{L} / \mathrm{min}$. No ion suppression was observed.

\section{Assay validation}

Assay calibration for $25 \mathrm{OHD} 3$ and $250 \mathrm{HD} 2$ was performed with 25OHD2 and 25OHD3 at five concentrations prepared by serial dilution in absolute ethanol and stored at $-70^{\circ} \mathrm{C}$ until use. Quantitation was achieved based on the peak area ratios of analytes to the internal standard. The $d_{6}-25 O H D 3$ was used as the internal standard for both 25OHD3 and 25OHD2 due to the fact that $d_{6}-25 O H D 2$, while recently available, has a molecular weight of 418.2. With the loss of a water molecule from $d_{6}-250 H D 2$ parent ion, a fragment with $401.2 \mathrm{~m} / \mathrm{z}$ was formed interfering with 25OHD3 quantification. The limit of detection was
$1.7 \mathrm{nmol} / \mathrm{L}$ and $1.2 \mathrm{nmol} / \mathrm{L}$ for $25 \mathrm{OHD} 3$ and $25 \mathrm{OHD} 2$, respectively, determined using 20 replicates of saline. From serial dilutions, linearity was determined to be 3.0-283.6 nmol/L for $250 H D 3$ and $4.6-277.9 \mathrm{nmol} / \mathrm{L}$ for $25 \mathrm{OHD} 2$, with an accuracy of $88.7 \%-118.7 \%$ and $90.7 \%-100.3 \%$, respectively. The LLOQ was $3.0 \mathrm{nmol} / \mathrm{L}$ for $25 \mathrm{OHD} 3$ and $4.6 \mathrm{nmol} / \mathrm{L}$ for $25 \mathrm{OHD} 2$, respectively based on the precision and accuracy data in the linearity study (Table 2 ). The intra-assay and inter-assay CVs (3.8-14.2, Table 3) were determined using patient samples at three concentrations based on CLSI EP10A3 guidelines (43). No significant carryover was observed by testing the spiked patient samples with low $_{1}$ (mean: $10.2 \mathrm{nmol} / \mathrm{L}$ )-high (713.3 nmol/L)-low 2 (10.2 nmol/L) for $250 H D 2$ and low 1 (38.9 nmol/L)-high (577.1 nmol/L)-low 2 (41.2 nmol/L) for 25OHD3.

\section{Method comparison}

We compared the newly developed method with the DiaSorin RIA using left-over patient samples. The distribution of vitamin D concentrations was near a nor- 


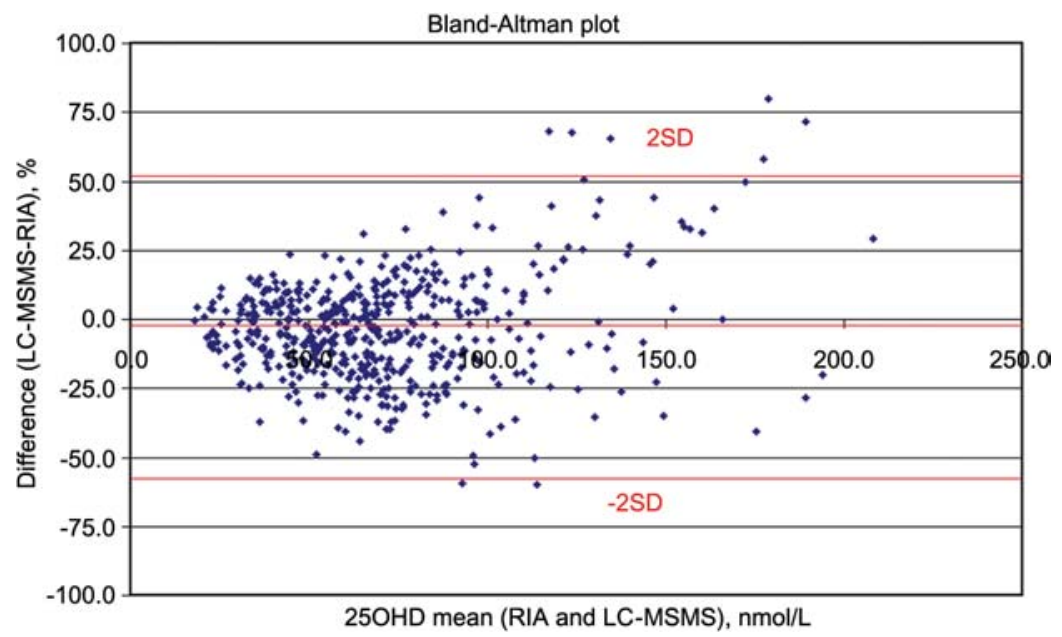

Figure 2 Bland-Altman plot. The mean of percent differences was $-7.6 \%$ with a standard deviation of $26.2 \%$.

mal distribution based upon visual inspection of the histogram of patient data (data not shown). Table 4 contains the comparison data using Deming regression between our LC-MSMS and the DiaSorin RIA method $(n=527)$. The regressions had a slope 0.87 , $r>0.84$, and mean difference within $5.2 \%$ using all samples $(n=527)$ or samples $(n=216)$ with 250 HD2 concentrations below the LLOQ, indicating equivalent recoveries of both 25OHD2 and 25OHD3 for the RIA method. To compare our results with a previously published comparison conducted between a LCMSMS method and several immunoassays, nonparametric Passing-Bablok regression $(n=527)$ was performed. The regression showed a slope of 0.96 (95\% Cl: $0.90-1.02)$ and an intercept of $6.64 \mathrm{nmol} / \mathrm{L}$ (3.74-10.14) which compared favorably to the slope of 0.64 (reverse relationship) between IDS-RIA (IDS Ltd., Tyne and Wear, UK) and LC-MSMS (24). A BlandAltman plot did not reveal concentration-depended bias between LC-MSMS and the RIA (Figure 2), as opposed to a previous observation between IDS-RIA and LC-MSMS (24). We calculated diagnostic agreement between LC-MSMS and RIA using $\geq 75 \mathrm{nmol} / \mathrm{L}$ as sufficient vitamin $D$ status and found this to be $80.9 \%$. For $0-50,51-74$ and $\geq 75.0 \mathrm{nmol} / \mathrm{L}$ cut-offs, agreement was $68.5 \%$ based on the deficient, insufficient, and sufficient levels commonly described in the literature (10). Under the 2nd diagnostic agreement breakdowns, LC-MSMS overestimated values $22.9 \%$ of the time and underestimated $8.6 \%$, compared to RIA. Multivariate regression was performed using all patient data $(n=527)$ to determine the contribution of 25OHD3 and 25OHD2 by our LC-MSMS to the total by RIA. The multivariate equation with $95 \% \mathrm{Cl}$ in parentheses was $\mathrm{RIA}=0.93(0.89-0.97) \times$ 25 OHD3 + 1.04(0.98-1.10) $\times 25$ OHD2, $\quad R^{2}=0.90$. This equation along with the correlation data demonstrated that the RIA method and LC-MSMS were comparable in determining $250 \mathrm{HD}$ concentrations in patient samples. Also, the difference between the two methods was much smaller than the difference observed between another LC-MSMS and the IDS RIA in a previous report (24). Therefore, our LC-MSMS method may be used in the clinical evaluation of serum 25OHD without significant overall deviation (mean difference $=5.2 \%$ ) from the RIA method, which has been used in many clinical trials. It is important to have comparable results obtained using different methodologies in clinical laboratories to avoid complication of clinical interpretation (44).

In conclusion, we developed and validated a novel LC-MSMS method with a turbulent flow online extraction technology to quantitate serum 25OHD2 and 250HD3. The method is rapid and requires little manual sample preparation. Our comparison study showed that the LC-MSMS provided comparable results with the DiaSorin RIA with a mean difference of only $5.2 \%$.

\section{Authors' disclosures of potential conflicts of interest}

No authors declared any potential conflicts of interest. The funding organizations played no role in the design of the study, review and interpretation of data, or preparation or approval of the manuscript.

\section{Acknowledgements}

This work was in part supported by SQI Diagnostics Systems (Toronto, Canada).

\section{References}

1. Holick MF. Sunlight and vitamin D for bone health and prevention of autoimmune diseases, cancers, and cardiovascular disease. Am J Clin Nutr 2004;80:1678S-88S.

2. Wolpowitz D, Gilchrest BA. The vitamin D questions: how much do you need and how should you get it? J Am Acad Dermatol 2006;54:301-17.

3. Grant WB. Epidemiology of disease risks in relation to vitamin D insufficiency. Prog Biophys Mol Bio 2006;92:6579.

4. Pfeifer M, Begerow B, Minne HW, Suppan K, FahrleitnerPammer A, Dobnig H. Effects of a long-term vitamin D and 
calcium supplementation on falls and parameters of muscle function in community-dwelling older individuals. Osteoporos Int 2009;20:315-22.

5. Tretli S, Hernes E, Berg JP, Hestvik UE, Robsahm TE. Association between serum 25(OH) D and death from prostate cancer. Br J Cancer 2009;100:450-4.

6. Gissel T, Rejnmark L, Mosekilde L, Vestergaard P. Intake of vitamin $\mathrm{D}$ and risk of breast cancer - a meta-analysis. J Steroid Biochem Mol Biol 2008;111:195-9.

7. Wei MY, Garland CF, Gorham ED, Mohr SB, Giovannucci E. Vitamin D and prevention of colorectal adenoma: a meta-analysis. Cancer Epidem Biomar 2008;17:2958-69.

8. Nagpal J, Pande JN, Bhartia A. A double-blind, randomized, placebo-controlled trial of the short-term effect of vitamin D-3 supplementation on insulin sensitivity in apparently healthy, middle-aged, centrally obese men. Diabet Med 2009;26:19-27.

9. Kim DH, Sabour S, Sagar UN, Adams S, Whellan DJ. Prevalence of hypovitaminosis D in cardiovascular diseases (from the National Health and Nutrition Examination Survey 2001 to 2004). Am J Cardiol 2008;102:15404.

10. Holick MF. Vitamin D deficiency. N Engl J Med 2007;357: 266-81.

11. Cranney A, Weiler HA, O'Donnell S, Puil L. Summary of evidence-based review on vitamin D efficacy and safety in relation to bone health. Am J Clin Nutr 2008;88:513S9S.

12. Vieth R. Vitamin D supplementation, 25-hydroxyvitamin D concentrations, and safety. Am J Clin Nutr 1999;69: 842-56.

13. Cashman KD, Hill TR, Lucey AJ, Taylor N, Seamans KM, Muldowney $\mathrm{S}$, et al. Estimation of the dietary requirement for vitamin $D$ in healthy adults. Am J Clin Nutr 2008;88:1535-42.

14. Trang HM, Cole DE, Rubin LA, Pierratos A, Siu S, Vieth R. Evidence that vitamin D3 increases serum 25hydroxyvitamin $\mathrm{D}$ more efficiently than does vitamin $\mathrm{D} 2$. Am J Clin Nutr 1998;68:854-8.

15. Leventis $P$, Kiely PDW. The tolerability and biochemical effects of high-dose bolus vitamin D2 and D3 supplementation in patients with vitamin D insufficiency. Scand J Rheumatol 2009;38:149-53.

16. Holick MF, Biancuzzo RM, Chen TC, Klein EK, Young A, Bibuld D, et al. Vitamin D2 is as effective as vitamin D3 in maintaining circulating concentrations of 25-hydroxyvitamin D. J Clin Endocrinol Metab 2008;93:677-81.

17. Zerwekh JE. Blood biomarkers of vitamin D status. Am J Clin Nutr 2008:87:1087S-91S.

18. Norman AW, Bouillon R, Whiting SJ, Vieth R, Lips P. 13th workshop consensus for vitamin $D$ nutritional guidelines. J Steroid Biochem Mol Biol 2007;103:204-5.

19. Cherniack EP, Florez H, Roos BA, Troen BR, Levis S. Hypovitaminosis $D$ in the elderly: from bone to brain. $J$ Nutr Health Aging 2008;12:366-73.

20. Saintonge $S$, Bang $H$, Gerber LM. Implications of a new definition of vitamin $D$ deficiency in a multiracial US adolescent population: the National Health and Nutrition Examination Survey III. Pediatrics 2009;123:797-803.

21. Carter GD, Carter R, Jones J, Berry J. How accurate are assays for 25-hydroxyvitamin D? Data from the International Vitamin D External Quality Assessment Scheme. Clin Chem 2004;50:2195-7.

22. Binkley N, Krueger D, Cowgill CS, Plum L, Lake E, Hansen $K E$, et al. Assay variation confounds the diagnosis of hypovitaminosis D: a call for standardization. J Clin Endocrinol Metab 2004;89:3152-7.

23. Glendenning P, Taranto M, Noble JM, Musk AA, Hammond C, Goldswain PR, et al. Current assays overestimate 25-hydroxyvitamin D-3 and underestimate 25-hydroxyvitamin D-2 compared with HPLC: need for assay-specific decision limits and metabolite-specific assays. Ann Clin Biochem 2006;43:23-30.

24. Roth HJ, Schmidt-Gayk H, Weber H, Niederau C. Accuracy and clinical implications of seven 25-hydroxyvitamin D methods compared with liquid chromatographytandem mass spectrometry as a reference. Ann Clin Biochem 2008;45:153-9.

25. Lensmeyer GL, Wiebe DA, Binkley N, Drezner MK. HPLC method for 25-hydroxyvitamin D measurement: comparison with contemporary assays. Clin Chem 2006; 52:1120-6.

26. Turpeinen U, Hohenthal U, Stenman UH. Determination of 25-hydroxyvitamin D in serum by HPLC and immunoassay. Clin Chem 2003;49:1521-4.

27. Hollis BW, Horst RL. The assessment of circulating 25(OH)D and 1,25(OH)(2)D: where we are and where we are going. J Steroid Biochem Mol Biol 2007;103:473-6.

28. Maunsell Z, Wright DJ, Rainbow SJ. Routine isotopedilution liquid chromatography-tandem mass spectrometry assay for simultaneous measurement of the 25-hydroxy metabolites of vitamins D-2 and D-3. Clin Chem 2005;51:1683-90.

29. Singh RJ, Taylor RL, Reddy GS, Grebe SK. C-3 epimers can account for a significant proportion of total circulating 25-hydroxyvitamin D in infants, complicating accurate measurement and interpretation of vitamin $D$ status. J Clin Endocrinol Metab 2006;91:3055-61.

30. Higashi T, Awada D, Shimada K. Simultaneous determination of 25-hydroxyvitamin D-2 and 25-hydroxyvitamin D-3 in human plasma by liquid chromatographytandem mass spectrometry employing derivatization with a Cookson-type reagent. Biol Pharm Bull 2001;24: 738-43.

31. Aronov PA, Hall LM, Dettmer K, Stephensen CB, Hammock BD. Metabolic profiling of major vitamin D metabolites using Diels-Alder derivatization and ultra-performance liquid chromatography-tandem mass spectrometry. Anal Bioanal Chem 2008;391:1917-30.

32. Vogeser M, Kyriatsoulis A, Huber E, Kobold U. Candidate reference method for the quantification of circulating 25hydroxyvitamin D-3 by liquid chromatography-tandem mass spectrometry. Clin Chem 2004;50:1415-7.

33. Tsugawa N, Suhara Y, Kamao M, Okano T. Determination of 25-hydroxyvitamin $D$ in human plasma using high-performance liquid chromatography-tandem mass spectrometry. Anal Chem 2005;77:3001-7.

34. Chen HP, McCoy LF, Schleicher RL, Pfeiffer CM. Measurement of 25-hydroxyvitamin D-3 (25OHD(3)) and 25hydroxyvitamin D-2 (25OHD(2)) in human serum using liquid chromatography-tandem mass spectrometry and its comparison to a radioimmunoassay method. Clin Chim Acta 2008;391:6-12.

35. Saenger AK, Laha TJ, Bremner DE, Sadrzadeh SM. Quantification of serum 25-hydroxyvitamin D2 and D3 using HPLC-tandem mass spectrometry and examination of reference intervals for diagnosis of vitamin D deficiency. Am J Clin Pathol 2006;125:914-20.

36. Capote FP, Jimenez JR, Granados JM, de Castro MD. Identification and determination of fat-soluble vitamins and metabolites in human serum by liquid chromatography/triple quadrupole mass spectrometry with multiple reaction monitoring. Rapid Commun Mass Sp 2007; 21:1745-54.

37. Grant RP, Cameron C, Mackenzie-McMurter S. Generic serial and parallel on-line direct-injection using turbulent flow liquid chromatography/tandem mass spectrometry. Rapid Commun Mass Sp 2002;16:1785-92.

38. Zimmer D, Pickard V, Czembor W, Muller C. Comparison of turbulent-flow chromatography with automated solidphase extraction in 96-well plates and liquid-liquid extraction used as plasma sample preparation tech- 
niques for liquid chromatography-tandem mass spectrometry. J Chromatogr A 1999;854:23-35.

39. Morzycki JW, Schnoes HK, Deluca HF. Synthesis of 25hydroxyvitamin-D2 and its 24-epimer. J Org Chem 1984; 49:2148-51.

40. O'Neil MJ. The Merck index: an encyclopedia of chemicals, drugs, and biologicals, 14th ed. Whitehouse Station, NJ: Merck, 2006;1:266.

41. Kostiainen R, Kauppila TJ. Effect of eluent on the ionization process in liquid chromatography-mass spectrometry. J Chromatogr A 2009;1216:685-99.
42. Uran S, Larsen $\AA$, Jacobsen PB, Skotland T. Analysis of phospholipid species in human blood using normalphase liquid chromatography coupled with electrospray ionization ion-trap tandem mass spectrometry. J Chromatogr B Biomed Life Sci Appl 2001;758:265-75.

43. Clinical and Laboratory Standards Institute. Preliminary evaluation of quantitative clinical laboratory measurement procedures; Approved Guideline, 3rd ed. Wayne, PA, 2006.

44. Fraser WD. Standardization of vitamin D assays: art or science? Ann Clin Biochem 2009;46:3-4. 